\title{
基 \\ Efeito da suplementação com concentrados ricos em óleo sobre biomarcadores metabólicos para cavalos
}

[Effects of supplementation with concentrates rich in oil over metabolic biomarkers in horses]

\section{"Artigo Científico/Scientific Article"}

\author{
Fernando Jorge Rodrigues Magalhães ${ }^{1}$, Tito Alves Santiago ${ }^{1}$, \\ Helena Emília Cavalcanti da Costa Cordeiro Manso ${ }^{1}$, José Mário Girão Abreu ${ }^{2}$, \\ Lúcia Maia Cavalcanti Ferreira ${ }^{1}$, Helio Cordeiro Manso Filho ${ }^{1 *}$
}

\footnotetext{
${ }^{1}$ Núcleo de Pesquisa Equina, Departamento de Zootecnia, Universidade Federal Rural de Pernambuco, Recife-PE, Brasil.

${ }^{2}$ Faculdade de Medicina Veterinária, Universidade Estadual do Ceará, Fortaleza-CE, Brasil.

*Autor para correspondência/Corresponding author: E-mail: helio.mansofo@ufrpe.br
}

\section{Resumo}

A performance dos cavalos atletas tem melhorando com a elevação da percentagem do extrato etéreo (EE) nos concentrados. Assim, avaliou-se a suplementação de concentrados com diferentes percentagens de EE sobre biomarcadores metabólicos em cavalos atletas, através de um fatorial com cinco equinos e cincos tratamentos [6,5\% $\mathrm{EE}(\mathrm{T} 6,5 \%), 8 \% \mathrm{EE}(\mathrm{T} 8,0 \%), 12 \% \mathrm{EE}(\mathrm{T} 12,0 \%), 14 \% \mathrm{EE}(\mathrm{T} 14,0 \%)$ e $20 \% \mathrm{EE}(\mathrm{T} 20,0 \%)]$. Os animais receberam suplementação isocalórica por 15 dias e no 160 dia colheu-se sangue nas fases inicial e jejum e após $1 / 2$ hora, 1, 2, 3, 4, 5 e 6 horas da ingestão dos alimentos. O sangue total foi utilizado para determinar hematrócrito, glicose, proteína plasmática total, ureia, creatinina, triglicérides e colesterol total. Os resultados demonstraram que ocorreu variação na [glicose] $(\mathrm{P}<0,05)$ na fase da colheita de sangue, mas sem diferenças $(\mathrm{P}>0,05)$ entre os tratamentos e na interação concentrado $\mathrm{x}$ fase. Também não ocorreram diferenças $(\mathrm{P}>0,05)$ no pico da [glicose] entre tratamentos e entre área sob a curva. Os demais biomarcadores analisados não sofreram modificação $(\mathrm{P}>0,05)$. Concluiu-se que a suplementação isoenergética com concentrados utilizando diferentes percentagens de EE não produzem modificações nos biomarcadores analisados, indicando que variações no EE podem ser utilizados, entre 6,5 e 20\%, para equinos atletas de forma similar.

Palavras-Chave: glicose; triglicérides; ureia, nutrição, equino.

\begin{abstract}
The performance of athletic horses had been improved with the elevation of the fat percentagem (EE) in concentrates. The objetive of this research was evaluate the supplementation with concentrate with different levels of EE over metabolic biomarkers in athletic horses, using a latin square with five horses and 5 treatments (6,5\% EE (T6,5\%), 8\% EE (T8,0\%), 12\% EE (T12,0\%), 14\% EE (T14,0\%) e 20\% EE (T20,0\%)). Animais received their isocaloric supplementation during 15 days and at 16th day, we did blood collection in these period: overnight fastening and after 0.5, 1.0, 2.0, 3.0, 4.0, 5.0 e 6.o hours after they were fed. Blood was used to determine: hematocrit, glucose, total plasma protein, urea, creatinine, triglycerides, and total cholesterol. Results were anylaszed by ANOVA, with two factores and repeated measurements, and Tukey test, both with $\mathrm{P}<0.05 \%$. Results showed variation in [Glucose] during blood collection phases $(\mathrm{P}<0.05)$, but without differences between treatments and the interaction treatment and phases $(\mathrm{P}>0.05)$. Also, there was no difference at the [glucose] peak between treatment and area under the curve $(\mathrm{P}>0.05)$. All other biomarkers did not change $(\mathrm{P}>0.05)$. In conclusion, isoenergetic supplementation with concentrates with different levels of fat did not produce changes in analyzed biomarkers, showing that variation in EE, between 6,5 and 20.0\%, may be used for equine athletes similarly.
\end{abstract}

Keywords: glucose; triglycerides; urea; nutrition; equine. 


\section{Introdução}

Nas últimas décadas ocorreram aumentos no número e na variedade de competições equestres no Brasil e, com isso, a indústria de nutrição animal introduziu novos conceitos e programas nutricionais com o objetivo de favorecer a performance e o bem-estar dos animais atletas. Esses conceitos atuais, com base em pesquisas científicas e no novo padrão de arraçoamento para cavalos (NRC, 2007), mostram que a inclusão de óleos e as formas recentes de processamento da ração, como extrusamento e floculagem, elevam a densidade energética, reduzem os riscos da suplementação com concentrados e aumenta a disponibilidade pré-cecal de nutrientes para a performance dos atletas (Ralston, 2008; Harris e Geor, 2009; Gobesso et al., 2011).

No mercado nacional existem produtos com diferentes percentagens de extrato etéreo (EE) que ainda são pouco utilizados nas criações de cavalo. A inclusão de óleo na ração dos animais atletas favorece a economia do glicogênio intramuscular em diferentes níveis de exercício, aumenta o tempo para a fadiga e contribui para o bem-estar desse grupo de animais, bem como podem ser utilizados para o tratamento de determinadas enfermidades musculares nos equinos (Ribeiro et al, 2004; Ralston, 2008; Harris e Geor, 2009). A inclusão de óleo acrescida de processos, como o extrusamento nas rações, favorece a digestibilidade pré-cecal, reduz as possíveis modificações na microbiota intestinal e contribui para a saúde do trato digestivo, principalmente dos atletas que são normalmente suplementados com quantidades elevadas de concentrados (Ralston, 2008; Hoffman, 2009).

Devido as novas características de produção industrial dos concentrados e da possibilidade de utilização de alimentos ricos em óleo, em diferentes programas nutricionais para equinos, foi desenvolvida uma pesquisa que objetivou a avaliação dos efeitos da suplementação de concentrados com diferentes percentagens de extrato etéreo sobre diferentes biomarcadores metabólicos em equinos. Assim, objetivou-se determinar se a caracterização desses possíveis efeitos sobre alguns biomarcadores poderá contribuir para o uso mais adequando desses produtos, bem como para reduzir os custos nas criações e manutenção de cavalos atletas.

\section{Material e Métodos Animais}

Foram utilizados cinco equinos Puro-Sangue Árabe em fase de manutenção, com idade média de
13 anos e peso aproximado de $400 \mathrm{~kg}$. Os animais permaneceram em piquetes formados com pastagens naturais, sendo ainda suplementados com feno de Tifton 85 (Cynodon nlemfluensis) ad libitum, além de livre acesso à água e ao sal mineralizado (Kromium, DSM Tortuga).

O experimento foi conduzido no Núcleo de Pesquisa Equina da Universidade Federal Rural de Pernambuco. Antes de cada etapa da experimentação, os animais foram pesados com fita de pesagem para equinos e a porcentagem de gordura corporal foi determinada por ultrassonografia, com transdutor de $5 \mathrm{MHz}$ (Mindray DP 2200), a partir da camada de gordura na garupa, conforme utilizado por Manso Filho et al. (2009).

\section{Grupos experimentais e programa de suplementação}

Os equinos foram aleatoriamente distribuídos em um fatorial 5x5 (cinco tratamentos com cinco animais), sendo cada tratamento foi repetido 5 vezes, de acordo com a porcentagem de extrato etéreo (EE) utilizado para cada tratamento (T). Os concentrados foram formulados com $6,5 \%$ de EE, $\left(\mathrm{T}_{6,5 \%}\right), 8,0 \%$ de $\mathrm{EE}\left(\mathrm{T}_{8,0 \%}\right), 12,0 \%$ de EE $\left(\mathrm{T}_{12,0 \%}\right), 14,0 \%$ de $\mathrm{EE}\left(\mathrm{T}_{14,0 \%}\right)$ e $20,0 \%$ de $\mathrm{EE}$ $\left(\mathrm{T}_{20,0 \%}\right)$.

Durante o período experimental, os animais foram isocaloricamente suplementados, em cochos individuais, com 7,0 Mcal/dia/animal divididas em duas refeições ofertadas às 08:00 e às 17:00 horas. A energia fornecida pelo concentrado correspondeu a $50 \%$ da energia necessária para animais em fase de manutenção (NRC, 2007) e as demais necessidades foram obtidas das forragens.

Os animais foram suplementados durante 15 dias e na manhã do $16^{\circ}$ dia foram iniciadas as colheitas de sangue, sendo a primeira com os animais em jejum alimentar de 12 horas e as demais após o fornecimento do concentrado. Ao final de cada fase experimental, os animais permaneceram em piquetes durante 21 dias sem receberem suplementação concentrada, mas com livre acesso a água e ao sal mineralizado, além de poderem interagir entre si e expressar seu comportamento característico. Antes de cada nova repetição, os animais não foram submetidos a uma fase de adaptação.

\section{Colheita de sangue e análises}

As amostras de sangue foram colhidas por venopunção, em tubos à vácuo previamente 
resfriados contendo ou não heparina. A primeira colheita ocorreu com os animais em jejum (F1) e, em seguida, os animais receberam o concentrado do respectivo tratamento. Após o arraçoamento, as demais colheitas de sangue foram realizadas após $+1 / 2$ hora $(\mathrm{F} 2),+1$ hora $(\mathrm{F} 3),+2$ horas $(\mathrm{F} 4),+3$ horas (F5), +4 horas (F6), +5 horas (F7) e +6 horas (F8).

As amostras de sangue foram utilizadas para determinação da glicose, proteína plasmática total, hematócrito, ureia, creatinina, colesterol total e triglicérides. A concentração da glicose plasmática ([GLIC]) foi determinada em aparelho portátil (ACCU-CHECK ADVANTAGE II, Roche ${ }^{\circledR}$ ) validado para uso em equinos, segundo Hackett e McCue (2010). A concentração das proteínas plasmáticas totais ([PPT]) foi determinada pela refratometria (Refratometro Portátil, ATAKO) e o hematócrito (HT) pela técnica do microhematócrito, segundo Wanderley et al. (2010). As concentrações de ureia ([UREIA]), creatinina ([CREAT]), colesterol total ([COLE-T]) e triglicérides ([TRIG]) foram realizados através do uso de kits comerciais (DOLLES ${ }^{\circledR}$ Reagentes) em equipamento semiautomático (BIO-200F, BioPlus ${ }^{\circledR}$ ). A área sob a curva da glicose e a quantidade de carboidratos não-estruturais foram calculadas conforme Harris \& Geor (2009).

As análises bromatológicas dos alimentos foram realizadas no Instituto de Pesquisa Agronômicas (IPA) de Pernambuco. Os técnicos envolvidos com as análises, tanto bioquímicas quanto bromatológicas, não tiveram acesso a distribuição das rações e as fases dos experimentais.

\section{Análise estatística}

Os resultados foram submetidos à análise da variância, com dois fatores e para medidas repetidas, sendo que um fator foi o tipo de concentrado (tratamento) e o outro foi a fase da colheita de sangue (tempo). O método de Tukey foi utilizado para a comparação múltipla entre as médias, quando necessário. Em todos os casos o nível de significância foi estabelecido em $\mathrm{P}<0,05$, e foi utilizado o programa SigmaPlot ${ }^{\circledR} 13.0$ (Systat Software Ins., San Jose-CA, USA) e os resultados estão expressos em médias +/- erro padrão médio.

\section{Resultados}

Na Figura 1 constam os dados referentes a variação da concentração da glicose ([GLIC]). Não foi observada diferença entre os tratamentos $(\mathrm{P}>$
$0,05)$, entretanto, constatou-se diferença $(\mathrm{P}<0,05)$ entre as fases da colheita de sangue dentro dos tratamentos. Não houve interação entre os tratamentos e as fases $(\mathrm{P}>0,05)$. Também não ocorreram diferenças $(\mathrm{P}>0,05)$ no pico da [GLIC] entre os tratamentos $(\mathrm{P}>0,05)$, com maior pico observado no $\mathrm{T}_{\mathbf{8 , 0} \%}(\sim 8,3 \mathrm{mmol} / \mathrm{L})$ e o menor no $\mathrm{T}_{20,0 \%}(\sim 6,5 \mathrm{mmol} / \mathrm{L})$. $\mathrm{Na}$ área sob a curva dos concentrados, o $\mathrm{T}_{12} \%$ apresentou a maior área $(\sim 41,5)$ e o $\mathrm{T}_{6,5 \%}$ a menor $(\sim 39,1)$, também não ocorreram diferenças $(\mathrm{P}>0,05)$. Em todos os tratamentos a [GLIC] observada no pico foi diferente $(\mathrm{P}<0,05)$ dos valores observados tanto no jejum quanto após 6 horas do fornecimento do concentrado (Tabela 1). Os demais biomarcadores não variaram significativamente $(\mathrm{P}<0,05)$, tanto nas fases de colheita quanto entre os tratamentos (Figura 2).

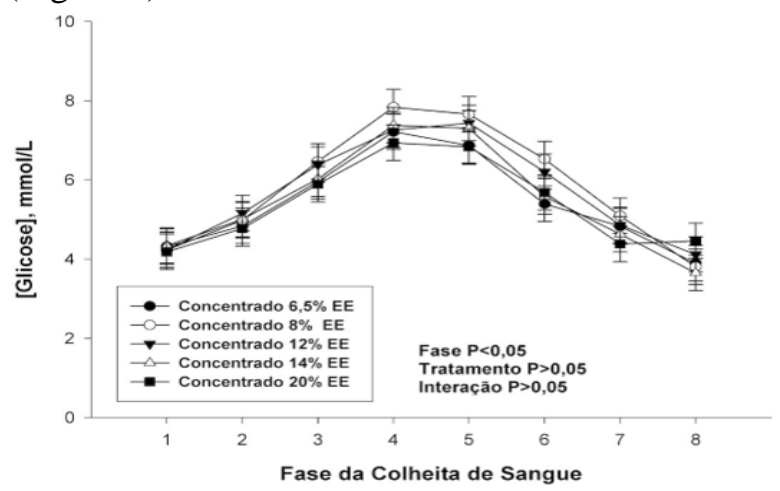

Figura 1. Concentração da glicose nos grupos experimentais, utilizando concentrados com diferentes percentagens de extrato etéreo, tanto em jejum (F1) quanto nas diferentes fases pós-prandial $[+1 / 2$ hora (F2), +1 hora (F3), +2 horas (F4), +3 horas (F5), +4 horas (F6), +5 horas $(\mathrm{F} 7)$ e +6 horas $(\mathrm{F} 8)]$.

Ainda observou-se que todos os animais em todas as fases consumiram o concentrado em um período máximo de 15 minutos após o fornecimento. Os resultados das análises bromatológicas e da percentagem de carboidratos não estruturais dos alimentos estão contidos na Tabela 2. Também não ocorreram modificações na massa corporal $(\sim 400,0 \mathrm{Kg})$ e tampouco na percentagem de gordura $(\sim 11,5 \%)$ ao longo de todo o período experimental $(\mathrm{P}>0,05)$.

Durante as fases das colheitas de sangue, ao longo das fases de suplementação e de "wash-out" não foram observados problemas de saúde que pudessem ser associados a ingestão dos concentrados experimentais. Além disso, as fezes dos animais não apresentaram alterações de suas características macroscópicas (coloração, consistência e odor). 

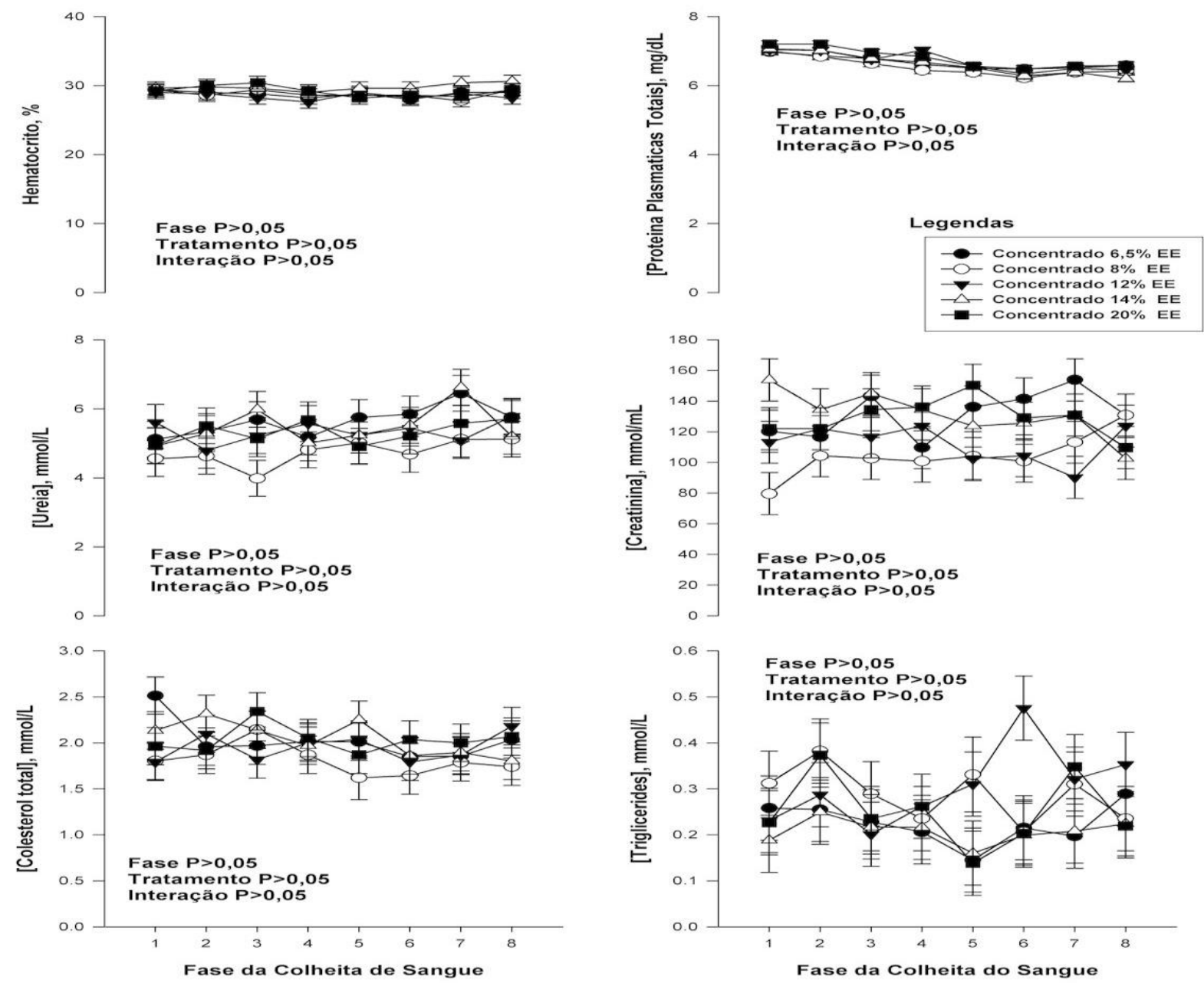

Figura 2. Hematócrito e concentrações dos diferentes biomarcadores metabólicos nos grupos experimentais utilizando concentrados com diferentes percentagens de extrato etéreo, tanto em jejum (F1) quanto nas diferentes fases pósprandial $[+1 / 2$ hora $(\mathrm{F} 2),+1$ hora $(\mathrm{F} 3),+2$ horas $(\mathrm{F} 4),+3$ horas $(\mathrm{F} 5),+4$ horas $(\mathrm{F} 6),+5$ horas $(\mathrm{F} 7) \mathrm{e}+6$ horas $(\mathrm{F} 8)]$.

Tabela 1. Concentração da glicose nos grupos experimentais utilizando concentrados com diferentes percentagens de extrato etéreo, no jejum, no pico da curva e após 6 horas da suplementação, assim como da área sob a curva da glicose plasmática nos grupos experimentais.

\begin{tabular}{|c|c|c|c|c|}
\hline \multirow{2}{*}{ Tratamento } & \multicolumn{3}{|c|}{ Glicose (mmol/L) } & \multirow{2}{*}{$\begin{array}{c}\text { Área sob a } \\
\text { curva da glicose }\end{array}$} \\
\hline & Jejum & Máxima & +6 horas & \\
\hline T 6,5\% & $4,32 \pm 0,05^{\mathbf{A a}}$ & $7,53 \pm 0,49^{\mathbf{A b}}$ & $3,90 \pm 0,19$ Aa & $39,2 \pm 2,3^{\mathbf{A}}$ \\
\hline Т 8,0\% & $4,23 \pm 0,10^{\mathbf{A a}}$ & $8.29 \pm 0,56^{\mathrm{Ab}}$ & $3,81 \pm 0,38^{\text {Aa }}$ & $42,6 \pm 2,5^{\mathrm{A}}$ \\
\hline T 12,0\% & $4,24 \pm 0,10^{\mathbf{A a}}$ & $7,73 \pm 0,81^{\mathbf{A b}}$ & $4,12 \pm 0,24{ }^{\mathrm{Aa}}$ & $41,5 \pm 3,8^{\mathbf{A}}$ \\
\hline T 14,0\% & $4,34 \pm 0,26^{\mathrm{Aa}}$ & $7,68 \pm 0,71^{\mathbf{A b}}$ & $3,65 \pm 0,49^{\mathrm{Aa}}$ & $39,9 \pm 2,2^{\mathbf{A}}$ \\
\hline T 20,0\% & $4,18 \pm 0,12^{\mathrm{Aa}}$ & $7,28 \pm 0,83^{\mathbf{A b}}$ & $4,46 \pm 0,25^{\mathrm{Aa}}$ & $40,6 \pm 2,6^{\mathrm{A}}$ \\
\hline
\end{tabular}

Letras diferentes na mesma coluna (maiúscula) e na mesma linha (minúsculas) indicam diferença (P<0,05) pelo teste de Tukey. A área sob a curva só foi comparada entre os tratamentos (coluna); Área sob a curva foi calculada conforme Harris \& Geor, 2009. 
Tabela 2. Análises bromatológicas dos alimentos utilizados nos diferentes tratamentos experimentais.

\begin{tabular}{lcccccc}
\hline \multirow{2}{*}{ Alimentos } & \multicolumn{7}{c}{ Componente do alimento (\% da MS) } \\
\cline { 2 - 7 } & MS & PB & EE & RM & FDN & CNE* \\
\hline Feno de Tifton & 90,9 & 8,7 & 2,4 & 7,2 & 84,4 & ----- \\
T 6,5\% & 89,9 & 16,5 & 6,5 & 13,5 & 34,9 & 45,1 \\
T 8,0\% & 89,6 & 14,6 & 8,0 & 9,0 & 32,4 & 36,0 \\
T 12,0\% & 90,7 & 16,4 & 11,7 & 7,0 & 38,0 & 26,9 \\
T 14,0\% & 92,6 & 16,1 & 13,9 & 9,1 & 22,3 & 31,6 \\
T 20,0\% & 92,3 & 14,7 & 19,6 & 8,3 & 28,9 & 32,6
\end{tabular}

MS: matéria seca; PB: proteína bruta; EE: extrato etéreo; RM: resíduo mineral; FDN: fibra degradada em detergente neutro; CNE: carboidratos não estruturais. *cálculos para determinação dos CNE: 100 - (PB\% + FDN\% + Umidade\% + EE\% + RM\%) (Harris e Geor, 2009).

\section{Discussão}

Diferentes estudos têm demonstrado que a quantidade de gordura no concentrado pode interferir na variação da [GLIC] sanguínea dos animais e também de como o alimento é digerido e absorvido nas diversas porções do aparelho digestivo (Hambleton et al., 1980; Ralston, 2008; Hoffman, 2009; Geelen et al., 2001). No atual experimento não foram observadas variações significativas nas diferentes avaliações da glicose sanguínea (jejum, pico, área sob a curva e a curva) entre os tratamentos, mesmo com os concentrados apresentando diferenças entre a percentagem de EE e na quantidade de carboidratos não-estruturais (CNE). Entretanto, deve-se considerar que os cavalos só estão plenamente adaptados, do ponto de vista metabólico à inclusão de óleos, após quatro ou oito semanas (Hambleton et al., 1980; Geelen et al., 2001) e no atual experimento esse período foi de apenas duas semanas.

A [GLIC] observada com os animais em jejum estava dentro da normalidade para a espécie (Ralston, 2008; Manso et al., 2015), assim como após seis horas da suplementação e assemelhava-se aos valores descritos na literatura para animais na região (Wanderley et al., 2010; Santiago et al., 2014). O pico da glicose também ocorreu, entre 120 e 180 minutos após a suplementação, de forma semelhante ao de outros trabalhos (Ralston e Baile, 1982; Healy et al., 1996; Witham e Stull, 1998). Deve-se ainda observar que o retorno da [GLIC] após seis horas já era esperado e assemelha-se aos resultados dos experimentos de Harris e Geor (2009), e Hoffman (2009). A combinação desses resultados indicam que os alimentos utilizados não afetaram a saúde dos animais, mesmo com uma composição bromatológica diferente. Ainda é importante ressaltar que esse fato contribui para demonstrar que alimentos ricos em EE podem ser utilizados com segurança para os equídeos, como previamente relatado por Mélo et al. (2012) e Barbosa et al. (2016).

Diferentes pesquisadores afirmam que uma baixa resposta glicêmica de um alimento rico em CNE, como é o caso do milho em grão não processado, pode produzir efeitos adversos no colo e ceco por modificar o microbioma dessas porções do intestino (Ralston, 2008; Harris e Geor, 2009; Hoffman, 2009; Manso et al, 2015). Esses fatos acima descritos podem ser importantes para a manutenção tanto da saúde do trato digestivo quanto da performance atlética dos cavalos de esporte, os quais normalmente apresentam consumo energético superior a $20 \mathrm{Mcal} / \mathrm{animal} / \mathrm{dia}$ (NRC, 2007). Os concentrados com maiores níveis de EE possuem maior densidade energética e, dessa forma, os cavalos poderão consumir mais energia em uma quantidade menor de concentrado sem sobrecarrega do aparelho digestivo, principalmente do microbioma no intestino grosso, como reportado por Ralston (2008); e Harris e Geor, (2009). Além disso, segundo Ralston (2008), Hoffman (2009) e Barbosa et al. (2016), alimentos que possuem quantidade de EE superior a $7 \%$ estão associados a utilização de partículas extrusadas ou floculadas, aspectos que favorecem também a digestão pré-cecal.

Variações simultâneas das [PPT] e do HT podem indicar perda ou sequestro de fluídos corporais para outras partes do corpo dos animais. McKeever et al. (2006) observaram que esses dois biomarcadores podem ser utilizados tanto como 
avaliadores da hidratação dos animais quanto como indicadores do nível de estimulação externa ao animal durante as colheitas de sangue. As ausências de variações significativas observadas nesses parâmetros eram esperadas tendo em vista que os animais consumiram água livremente ao longo do período de colheita de sangue, mas não receberam forragens, reduzindo assim o transporte de líquidos para o interior do trato digestivo. Os animais também foram mantidos estabulados, mas podendo interagir entre eles, em um ambiente calmo, livre de estresse ou que pudesse estimular a contração esplênica, que pode ocorrer em equinos submetidos ao exercício físico, como reportado por McKeever et al. (2006) e Santiago et al. (2014).

Diferentes pesquisa têm demonstrado que a inclusão de óleo em rações para cavalos podem não provocar modificações no perfil hematimétrico dos animais por favorecer a estabilidade da parede celular (Hambleton et al., 1980; Taylor et al., 1995). Recentemente, Mélo et al. (2012) relataram que a suplementação de potros apartados com concentrados rico em óleo ( $20 \%$ de EE) não foi capaz de modificar os parâmetros associados aos glóbulos vermelhos, no entanto, produziu redução na contagem de glóbulos brancos após 60 dias de suplementação. Deve-se ressaltar que alguns desses resultados podem ter relações com o tempo ideal de adaptação ao óleo, pois conforme Hambleton et al. (1980) e Geelen et al. (2001), seria superior a quatro semanas. Todavia, essas modificações na contagem das séries vermelha e branca não estão completamente esclarecidas durante a suplementação com óleos, principalmente os essenciais. Contudo, espera-se que a disponibilidade de óleos essenciais possa estabilizar a membrana plasmática e favorecer o aumento do tempo de vida das células mais capacitadas.

A [TRIG] e de [COLE-T] estão relacionadas com a digestão, absorção, produção e consumo desses biomarcadores no corpo dos cavalos. A determinação das [COLE-T] e [TRIG] são largamente utilizadas nas análises das possíveis adaptações ao uso das gorduras e outros alimentos para os equinos em diferentes condições (Fonnesbeck e Symons, 1969; OldruitenborghOosterbaan et al., 2002; Ribeiro et al., 2009; Mélo et al., 2012). Observando-se os valores das [COLE$\mathrm{T}]$ no atual experimento, constata-se que eles são similares aos descritos por outros autores (Geelen et al., 1999, Oldruitenborgh-Oosterbaan et al., 2002; Hambleton et al., 1980), os quais também não observaram diferença nas concentrações de colesterol entre os tratamentos de seus experimentos. Todavia, Hambleton et al. (1980), trabalhando com quatro níveis de óleo de soja na dieta $(4,8,12$ e 16\%), verificaram uma elevada correlação entre concentrações de colesterol e dietas, o que não foi observado no atual experimento, que não era esperado, mas esses autores utilizaram períodos mais longos de suplementação, confirmando que a duração da suplementação pode influenciar na concentração desse biomarcador.

A determinação do colesterol total e dos triglicerídeos também são largamente utilizados nas análises das possíveis adaptações ao uso das gorduras e outros alimentos para os equinos, além de serem importantes na avaliação dos cavalos atletas. Durante a execução deste experimento, observou-se que a [TRIG] não variou significativamente no que se refere ao tipo de ração e que essas concentrações estavam dentro das variações esperadas para cavalos sadios, conforme salientado por Wanderley et al. (2010) e Santiago et al. (2014). Ainda deve ser ressaltado que pesquisas realizadas por Marchello et al. (2000) e Geelen (2001) demonstraram que a [TRIG] não varia com a suplementação de gordura vegetal adicionada à dieta durante períodos mais longos que do atual experimento. Recentemente foi determinado por Mélo et al. (2012) que a suplementação com concentrado rico em óleo (20\% EE) não modificou a [TRIG], mas a de [COLE-T] em potros após oito semanas de suplementação. Esses resultados discrepantes podem estar relacionados não somente com a produção do TRIG, mas também com o seu consumo e quando o aporte de gorduras aumenta pode ocorrer redução na concentração desse biomarcador como forma de adaptação ao seu maior aporte.

Os biomarcadores do metabolismo protéico, como a ureia, que se origina da metabolização hepática de compostos nitrogenados, e a creatinina que é produzida a partir da decomposição da creatina, devem ser utilizados para se entender o efeito da suplementação com rações nos cavalos (Stockham, 1995). Relação positiva entre níveis de proteína bruta na dieta e concentração de ureia plasmática em cavalos foi observada por Sticker et al. (1995) e de acordo com Oliveira et al. (2002), aminoácidos oriundos da digestão de farelo de soja em excesso podem elevar as [UREIA] no sangue. Tanto a ureia quanto a creatinina sofrem 
influências de condições pré-renais, como intensa atividade ou alteração muscular e também devido à hipovolemia que leva à diminuição da filtração glomerular. Como neste experimento os animais utilizados eram sadios e não praticavam exercícios forçados, esperava-se que esse fatores não influenciassem sobre os resultados. Fonnesback e Symons (1969) observaram que pode haver modificações na [UREA], dependendo do tipo e da duração da suplementação para o equino ou do tipo de exercício que os animais estão submetidos, porém, no atual trabalho não foram detectadas modificações significativas das curvas de [UREA] e [CREAT] após a ingestão dos suplementos. Esses resultados não eram esperados, pois a proteína bruta dos concentrados experimentais variou de 8,7 até $16,5 \%$ da matéria seca, mas como observado nos biomarcadores das gorduras, esses biomarcadores protéicos também podem ser influenciados pela duração da suplementação. Esses resultados não eram esperados, pois os alimentos possuíam composições bromatológicas diferentes, principalmente a quantidade de carboidratos não estruturais, mas fatores como interação entre nutrientes e forma na qual os nutrientes estão disponíveis em determinado alimento pode ter interferido nos resultados, além deles terem sido fornecidos de forma isoenergética.

\section{Conclusão}

Os resultados permitem concluir que a suplementação de concentrados com extrato etério, entre 6,5 e $20 \%$ e de curta duração, não produz modificações na concentração sanguínea dos biomarcadores metabólicos analisados, com excessão da glicose pós-prandial, mas associada a fase da colheita e não ao tipo de concentrado utilizado.

\section{Conflito de Interesse}

Os autores declaram não existir conflito de interesse.

\section{Comitê de Ética}

Este projeto foi conduzido de acordo com as normas da comissão de uso de animais em pesquisa (62/2007-CTA/DZ/UFRPE).

\section{Agradecimentos}

A MaltaCleyton do Brasil S/A (São Lourenço da Mata-PE) pelo fornecimento das rações experimentais e ao CNPQ pelo suporte financeiro a esse projeto aos bolsistas do projeto.

\section{Referências}

Barbosa, B.L.; Silva, G.B.; Silva, C.J.F.L.; Ferreira, L.M.C.; Manso, H.E.C.C.C.; Manso Filho, H.M. Blood, Metabolic and Endocrine biomarkers in donkeys (Equus africanus asinus) supplemented with different energy sources. Acta Veterinaria Brasilica, 10(2): 135-143, 2016.

Fonnesbeck, P. V.; Symons, L. D. Effect of diet on concentration of protein, urea nitrogen, sugar and cholesterol of blood plama in horses. Journal of Animal Sciences, 28: 216-219, 1969.

Geelen, S. N. J.; Oldruitenborgh-Oosterbaan, M. M. S.; Beynem, A. C. Dietary fat supplementation and equine plasma lipid metabolism. Equine Veterinary Journal, 30: 475-478, 1999.

Geelen, S.N.J; Blazquez, C.; Math, J. H.; Geelen, M.J.H.; van Oldruitenborgh-Oosterbaan, M.M.S.; Beynen, A.C. High fat intake lowers hepatic fatty acid synthesis and raises fatty acid oxidation in aerobic muscle in shetland ponies. British Journal of Nutrition, 86(1): 31-36, 2001.

Gobesso, A.A.O.; Moreira, A.M.F.; Tamas, W.T.; Ribeiro, R.M.; Prezotto, L.D.; Gonzaga, I.V.F.; Etchichury, M.; Brandi, O. Digestibilidade aparente e concentrações plasmáticas de triglicérides e colesterol. Revista Brasileira de Saúde e Produção Animal, 12(1): 254-263, 2011.

Hackett, E.S.; McCue, P.M. Evaluation of a veterinary glucometer for use in horse. Journal of Veterinary Internal Medicine, 24(3): 617-621, 2010.

Hambleton, P.L.; Slade, L.M.; Hamar, D.W.; Kienholz, E.W.; Lewis, L.D. Dietary protein and fat effects on protein status in Arabian Horses during interval training repeated sprints. Journal Equine Veterinary Science, 51? 1330-1334, 1980.

Harris, P.; Geor, R. J. Primer on dietary, carbohydrate and utility of the glycemic index in equine nutrition. The Veterinary Clinics: Equine Practice, 25: 23-37, 2009.

Healy, H. P.; Siciliano, P. D.; Larence, L. M. Effect of concentrate form on blood and gastric fluid variables in ponies. Equine Nutrition Physiology Society, 15(10): 423-428, 1996.

Hoffman, R. M. Carbohydrate metabolism and metabolic disorders in horses. Revista Brasileira de Zootecnia, 38: 270-276, 2009. 
Manso Filho, H.C.; Manso, H.E.C.C.C.; Ferreira, L.M.C.; Santiago, T.A.; Wandreley, E.K.; Abreu, J.M.G. Percentagem de gordura em cavalos criados em região tropical. Acta Scientiae Veterinariae, 37(3): 239-243, 2009.

Manso, H.E.C.C. C.; Silva, A.E.M; Santiago, T.A.; Almeida, T.L.A.C.; Duarte, S.R.R.; Manso Filho, H.C. Biomarcadores sanguíneos de cavalos consumindo milho processado de diferentes formas ou farelo de algaroba. Revista Acadêmica Ciência Animal, 13: 71-79, 2015.

Marchello, E.V.; Schung, W.A.; Marchello, J.A.; Cuneo, S.P. Changes in lipoprotein composition in horses fed a fat supplemented diet. Journal of Equine Veterinary Science, 20(7): 453-458, 2000.

McKeever, J.M.; McKeever, K.H.; Alberici, J.M.; Gordon, M.E.; Manso Filho, H.C. Effect of omeprazole on markers of performance in gastric ulcer-free standardbred horses. Equine Veterinary Journal, 36: 668-671, 2006.

Mélo, S.K.M.; Vaz, S.G.; Manso, E.C.C.; Martins, I.D.S.L.; Hunka, M.M.; Manso, H.E.C.C.C; Manso Filho, H.C. Influência da suplementação com concentrado extrusado, rico em óleo, nos parâmetros hematológicos, biométricos e biomarcadores na digestão de potros. Medicina Veterinária (UFRPE), 6(4): 41-45, 2012

Nutrient Requirements of Horses (NRH). $6^{\text {th }}$ revised edition. Animal Nutrition series. National Research Council of the National Academies. Washington, DC (USA). 2007.

Oldruitenborgh-Oosterbaan, M.M.S.; Annee, M.P.; Verdegaal, E.J.; Lemmens, A.G.; Beynen, A.C. Exercise- and metabolism-associated blood variables in standardbreds fed either a low- or a high-fat diet. Equine Veterinary Journal, 34: 2932, 2002.

Oliveira, G.J.C.; Lima, J.A.F.; Araújo, K.V; Fialho, E.T.; Bertechini, A.G.; Perez, J.; Freitas, R.T.F. Influência da pectina sobre parâmetros fisiológicos em eqüinos. Ciência Agrotécnica, 26(4): 858-864, 2002.

Ralston, S. L. Influence of management on equine digestion. Revista Brasileira de Zootecnia, 37: 211-214, 2008.
Ralston, S.L.; Baile, C.A. Plasma glucose and insulin concentrations and feeding behavior in ponies. Journal of Animal Science, 54: 1132-1137, 1982.

Ribeiro, R.M.; Pastori, W.T.; Fagundes, M.H.R.; Prezotto, L.D.; Gobesso, A.A.O. Efeito da Inclusão de diferentes fontes lipídicas e óleo mineral na dieta sobre a digestibilidade dos nutrientes e os níveis plasmáticos de gordura para equiinos. Revista Brasileira de Zootecnia, 38(10): 1989-1994, 2009.

Ribeiro, W.P.; Valberg, S.J.; Pagan, J.D.; EssenGustavsson, B. The effect of varying dietary starch and fat content on serum creatine kinase activity and substrate availability in equine polysaccharide storage myopathy. Journal of Veterinary Internal Medicine, 18: 887-894, 2004.

Santiago, T.A.; Manso, H.E.C.C.C.; Abreu, J.M.G.; Melo, S.K.M.; Manso Filho, H.V. Blood biomarkers of the horse after field Vaquejada test. Comparative Clinical Pathology, 23: 769-775, 2014.

Sticker, L.S.; Thompson, D.L.; Bunting, L.D.; Fernandez, J.M.; DePew, C.L. Dietary protein and energy restriction in mares: plasma glucose, insulin, nonesterifield fatty acid, and urea nitrogen responses to feeding, glucose, and epinephrine. Journal of Animal Science, 73(1): 136-144, 1995.

Stockham, S. L. Interpretation of equine serum biochemical profile results. Veterinary clinics of North America: equine practice, 11(3): 393-408, 1995.

Taylor, L.E.; Ferrante, P.L.; Kronfeld, D.S.; Meacham, T.N. Acid-base variables during incremental exercise in sprint-trained horses fed a high fat diet. Journal of Animal Science, 73(7): 2009-2018, 1995.

Wanderley E.K.; Manso Filho, H.C.; Manso, H.E.C.C.C.; Santiago, T.A.; McKeever, K.H. Metabolic changes in four beat gaited horses after field marcha simulation. Equine Veterinary Journal, 42: 105-109, 2010.

Withan, C.L.; Stull, C.L. Metabolic responses of chronically starved horses to refeding three isoenergetic diets. Journal of America Veterinary Medicine Association, 212(5): 691-696, 1998. 